\title{
Sensitive and Rapid Voltammetric Determination of Phenothiazine and Azaphenothiazine Derivatives in Pharmaceuticals Using a Boron-doped Diamond Electrode
}

\author{
Katarzyna Mielech-ŁuKASIEWICZ ${ }^{\dagger}$ and Elżbieta STAŚKOWSKA \\ University of Biatystok, Institute of Chemistry, Biatystok 15-399, Poland
}

\begin{abstract}
Novel, sensitive and rapid electrochemical methods for the determination of phenothiazine and azaphenothiazine derivatives were developed. A boron-doped diamond (BDD) electrode was used for electrochemical oxidation of levomepromazine, promazine and prothipendyl. The electrooxidation of these substances demonstrated reversible peaks of oxidation at the potential range $0.55-0.75 \mathrm{~V} v s$. SCE. Examining the influence of scan rate allowed is to demonstrate that the currents registered typical of the diffusion-controlled process. Determinations of the studied analytes were carried out by means of a square wave voltammetry (SWV) method and a differential pulse voltammetry (DPV) method. Linear ranges of determination with the use of the BDD electrode and the SWV method were obtained in the ranges: from $4 \times$ $10^{-7}$ to $1.38 \times 10^{-4} \mathrm{~mol} \mathrm{~L}^{-1}$ for levomepromazine, from $4 \times 10^{-7}$ to $1.17 \times 10^{-5} \mathrm{~mol} \mathrm{~L}^{-1}$ for promazine and from $4.95 \times$ $10^{-7}$ to $4.54 \times 10^{-5} \mathrm{~mol} \mathrm{~L}^{-1}$ for prothipendyl. The influence of interferences on the voltammetric signal of the studied analytes was also checked. The proposed procedures were used for quantitative determination of the studied compounds in pharmaceutical preparations. The measurements showed high accuracy. The recovery values obtained ranged from 98.52 to $99.57 \%$. The developed procedures were compared with pharmacopoeial reference methods.
\end{abstract}

Keywords Boron-doped diamond electrode, phenothiazine derivatives, azaphenothiazine derivatives, voltammetric analysis, pharmaceuticals

(Received January 25, 2015; Accepted May 15, 2015; Published October 10, 2015)

\section{Introduction}

Phenothiazine derivatives are a numerous group of organic compounds with valuable pharmacological properties. Because of their physiological activity, they are classified as psychoactive drugs and widely applied in the treatment of mental diseases. ${ }^{1,2}$ Phenothiazine derivatives have a tricyclic structure, with two rings of benzene connected with atoms of sulfur and nitrogen. One of the benzene rings can be replaced with pyridine. An azaphenothiazine structure is then formed (Fig. 1). Substituents in position 2 and 10 of the phenothiazine structure, the presence of chemically active atoms of sulfur and nitrogen in the aromatic structure, and the atom of nitrogen in the chain with the substituent, give these compounds high chemical activity.

Due to their valuable therapeutic and pharmacological properties, phenothiazine and azaphenothiazine derivatives are the subject of many scientific studies. Analytical application of these compounds is based on their reduction properties and the capacity to form colorful charge-transfer type complexes or ionassociation bonds. A literature review shows that the methods of determination of phenothiazine derivatives mainly include chromatographic $^{3-9}$ and spectrophotometric ones. ${ }^{10-15}$ With the development of modern pharmaceutical chemistry, the need arises to develop new methods of determination using

† To whom correspondence should be addressed.

E-mail: mielech@uwb.edu.pl contemporary analytical techniques. Electrochemical methods have been widely used in chemical analysis. Thanks to the application of modern measurement techniques and electrode materials, these methods provide broad research possibilities, also in the analysis of pharmaceutical preparations. Electroanalytical methods allow for automatization both in conducting the experiments and in result analysis, ensuring high sensitivity and precision of measurements. These methods are quick and do not require complex equipment, and they can be directly applied in studying several pharmaceutical dosage forms (e.g. tablets, injections, cream). Additional substances very often do not disturb the determinations, unlike in most other instrumental methods.

However, the number of publications concerning the use of electrochemical methods of phenothiazine and azaphenothiazine derivatives determination is significantly low compared to that for other methods. In the literature we can find descriptions of polarographic methods involving oxidation of phenothiazine derivatives to sulfoxides, followed by their reduction at dropping mercury electrode. ${ }^{16}$ Voltammetric methods described in the literature make use of metallic electrodes (e.g. Pt, $\mathrm{Au}, \mathrm{Ru})^{17-19}$ and different carbon electrodes. ${ }^{20-22}$ Some works are also described in which phenothiazine derivatives are electrocatalytically oxidized in the presence of methylene blue or alizarin red S used as mediators. ${ }^{23,24}$ Since phenothiazine derivatives are adsorbed on the surface of many electrodes, some methods are also proposed which include the stage of their controlled concentration on the surface of electrodes. ${ }^{25}$ Other 
<smiles>COc1ccc2c(c1)N(CC(C)CN(C)C)c1ccccc1S2</smiles>

A<smiles>CN(C)CCCN1c2ccccc2Sc2ccccc21</smiles>

B<smiles></smiles>

C

Fig. 1 Structures of levomepromazine (A), promazine (B) and prothipendyl (C).

methods are also described, using selective adsorption of phenothiazine derivatives on properly modified (e.g. with a DNA solution, ${ }^{26,27}$ cyclodextrins, ${ }^{28}$ dekanotiol, ${ }^{29} \mathrm{Pt}$ nanoparticle ${ }^{30}$ and multi-walled carbon nanotubes ${ }^{31-33}$ ) electrode surfaces.

This work presents experiments concerning electrochemical oxidation of selected phenothiazine and azaphenothiazine derivatives at a new electrode material, the boron-doped diamond (BDD) electrode. The BDD electrodes have attractive electrochemical properties, different to conventional ones. ${ }^{34-37}$ They have high chemical resistance and signal stability. Their wide potential band allows for the detection of compounds that react at relatively high potential values. The sensitivity and precision of determination are increased by good electrical conductivity of the electrodes and high signal to noise ratio. BDD electrodes are insensitive to oxygen dissolved in the examined solution, and this do not require oxygen elimination of the investigated solutions, which considerably shortens the time of analysis. They are used for determination of various biologically active substances, ${ }^{38-43}$ ions, elements and nonorganic compounds ${ }^{44-47}$ in different matrices.

The analyzed compounds (promazine, levomepromazine and prothipendyl) have not yet been studied and determined at the BDD electrode. A literature review shows that the BDD electrode has only been used for the flow injection analysis of chloropromazine with amperometric detection, ${ }^{48}$ and of promethazine with additional adsorption on the electrode surface. ${ }^{49}$ However, comparing the ranges of linear determination of the studied compounds in experiments described in the literature and the values obtained in this work, it can be concluded that the proposed study procedures have very similar determination ranges and do not require any modification of the measurement system. Besides, the proposed procedures ensure quick, direct analysis with high sensitivity and accuracy. The simplicity of the proposed procedures, combined with the use of sensitive electrochemical methods (differential pulse voltammetry and square wave voltammetry) makes them ideal for routine analyses.

\section{Experimental}

\section{Reagents and chemicals}

The electrochemical measurements were performed using a P128N potentiostat-galvanostat manufactured by Metrohm, Autolab. B.V. The apparatus was equipped with Nova computer software, which enables computer recording and analysis of data. The measurements were carried out in a three-electrode system including a working electrode, BDD; $\mathrm{A}=0.07 \mathrm{~cm}^{2}$; type D-035-SA (Windsor Scientific L., UK, diamond doped with boron, around $0.1 \%$ ), a platinum wire auxiliary electrode, and saturated calomel electrode (SCE) used as a reference electrode. A glassy carbon electrode $\left(A=0.07 \mathrm{~cm}^{2}\right.$, type MF-2012, Bioanalytical System, USA) was used for comparative tests.

BDD and GC electrodes were polished with an MF-2060 polishing kit from BAS, USA. The polishing kit contained aluminium oxide with $0.1,0.3$ and $1 \mu \mathrm{m}$ grains and polishing cloth from Buehler. The electrodes were polished for $2 \mathrm{~min}$, and then rinsed with water. In addition, the electrodes were electrochemically cleaned by multiple cycling in an appropriate potential range, using the scan rate $100 \mathrm{mV} / \mathrm{s}$. The small amounts of the studied substances absorbed on the surface of the BDD electrode were removed by holding it in ethanol solution.

Before each measurement, the glassy carbon electrode was deoxidized with argon for 10 min. Oxygen dissolved in the solutions did not interfere with the use of the BDD electrode during the experiments, so do not require oxygen elimination of the studied solutions.

The samples were weighed out on an electronic scale type PB-153 (Mettler Toledo, Switzerland). The $\mathrm{pH}$ was measured using a pH meter inoLab Level 1 (WTW, Germany). All the experiments were performed at ambient temperature.

Solutions of promazine hydrochloride and prothipendyl hydrochloride (Sigma) were prepared by dissolving appropriate weighed amounts of the substances in water. The solution of levomepromazine (Specia) was prepared in a water-ethanol solution $1: 1(\mathrm{v} / \mathrm{v})$

The supporting electrolytes were: $0.1 \mathrm{~mol} / \mathrm{L} \mathrm{KCl}, 0.1 \mathrm{~mol} / \mathrm{L}$ $\mathrm{HClO}_{4}, 0.1 \mathrm{~mol} / \mathrm{L} \mathrm{HCl}, 0.02 \mathrm{~mol} / \mathrm{L} \mathrm{H}_{3} \mathrm{PO}_{4}$ and the buffers were: Britton-Robinson (B-R) buffer $0.04 \mathrm{~mol} / \mathrm{L}$ with $\mathrm{pH} 1.8$ and 2.6, $0.1 \mathrm{~mol} / \mathrm{L}$ phosphate buffer with $\mathrm{pH} 2.0$ and $0.2 \mathrm{~mol} / \mathrm{L}$ acetate buffer with $\mathrm{pH}$ 3.6.

Analytical grade reagents and Milli-Q water with preliminary distillation (Millipore Corp., USA) were used to prepare the solutions.

\section{Tablet assay procedure}

A total of 10 tablets were weighed, ground down, and their average weight was determined. Then the tablet base corresponding to 1 tablet of the studied substance was weighed out. The weighed amount was quantitatively transferred to a $100 \mathrm{~mL}$ volumetric flask and dissolved in $50 \mathrm{~mL}$ of water. The solution prepared this way was mechanically shaken for $30 \mathrm{~min}$. Next the flask was complemented with water to the volume, and the solution was filtered under reduced pressure. An appropriate amount of the solution was taken from the filtrate to a $50 \mathrm{~mL}$ flask and complemented with water. The solutions of levomepromazine were complemented with water-ethanol solution (v/v, 1:1). Appropriate amounts of the studied substances were sampled from the working solutions and analyzed voltammetrically. During electrochemical tests, the 
optimum parameters were applied, as used to obtain the calibration graph.

\section{Results and Discussion}

Electrochemical behavior of phenothiazine and azaphenothiazine derivatives

Figure 2 presents a typical voltammogram of electrochemical oxidation of the phenothiazine derivative. The cyclic voltammogram of promazine with the concentration of $3.84 \times$ $10^{-4} \mathrm{~mol} / \mathrm{L}$ was recorded in $0.1 \mathrm{~mol} / \mathrm{L} \mathrm{HClO}_{4}$ in the potential range from -0.4 to $1.2 \mathrm{~V}$. In this potential range, a curve of the background was also made on the BDD electrode.

On the recorded voltammogram, two oxidation peaks are visible, at potentials of approx. 0.57 and $0.95 \mathrm{~V}$ respectively, and one reduction peak at the potential of approx. $0.5 \mathrm{~V}$. In addition, a cyclic voltammogram for promazine was made in the potential range $0.25-0.8 \mathrm{~V}$. On the basis of this voltammogram it was found that the first oxidation peak of promazine is related with the reduction peak. The obtained peaks are related with the reversible oxidation of the phenothiazine derivative to the radical cation. The obtained difference in potentials of oxidation

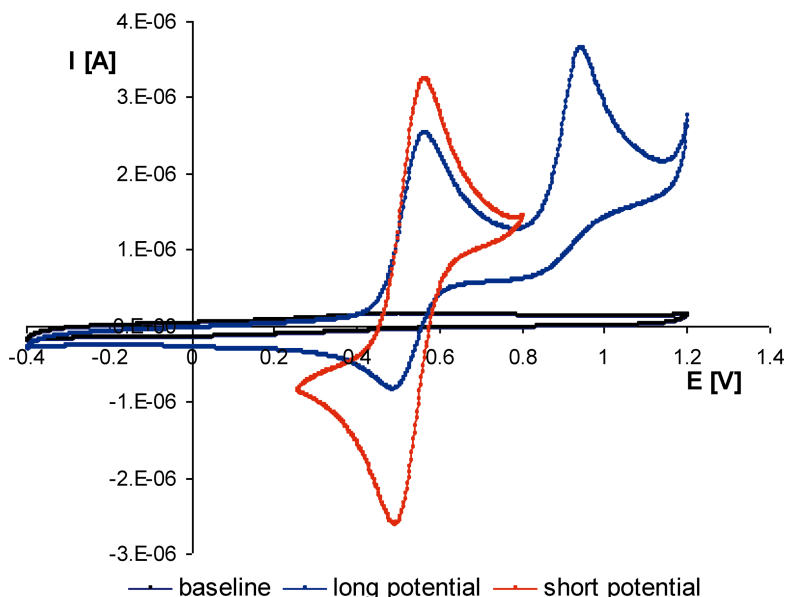

Fig. 2 Cyclic voltammograms of $3.84 \times 10^{-4} \mathrm{~mol} / \mathrm{L}$ promazine in $0.1 \mathrm{~mol} / \mathrm{L} \mathrm{HClO}_{4} ; \mathrm{v}=50 \mathrm{mV} / \mathrm{s}$ peak and reduction peak is approximately $60 \mathrm{mV}$ and is independent of scan rate (see next section), which suggests that is the one-electron reversible process. The second oxidation peak, at potential of approx. $0.95 \mathrm{~V}$ is related with the irreversible oxidation of the phenothiazine derivative to the dication or, according to some authors, related to the formation of a sulfoxide. ${ }^{2,20}$ In this step, the radical cation is irreversibly oxidized (by a loss of another electron) and phenothiazine ion is created. This ion is consequently easily hydrolyzed, resulting in the production of a sulfoxide. The presented cyclic voltammograms conform to the mechanism of electrooxidation of phenothiazine derivatives described in the literature ${ }^{2}$ (Fig. 3).

In the case of the other studied compounds (levomepromazine and prothipendyl), similar cyclic voltammograms were obtained. The work involved studies within the first reversible step of oxidation of the investigated compounds. Figure 4 presents the reversible processes of oxidation of these compounds to radical cations.

Studies of azaphenothiazine derivative (prothipendyl) showed a course of oxidation curves for that compound very similar to the cyclic voltammograms of levomepromazine and promazine. This suggests that, just like in the case of phenothiazine derivatives, prothipendyl oxidation occurs in the central ring, and the presence of extra nitrogen in the pyridine ring does not affect the mechanism of electrooxidation of that compound (Fig. 5).

The differences in the course of recorded voltammograms of levomepromazine, promazine and prothipendyl (Fig. 4) result from differences in the structure of $\mathrm{R}_{2}$ and $\mathrm{R}_{10}$ substituents. The potentials of oxidation peak and reduction peak are characteristic of each particular compound and depend on their chemical structure, especially on substituents in positions 2 and 10 of the phenothiazine ring. The potential values increase in the series $-\mathrm{OCH}_{3}<-\mathrm{H}$. This is in conformity with literature data. ${ }^{20}$ Furthermore, research has shown that the potential of azaphenothiazine derivative (prothipendyl) oxidation is higher than the potential of promazine oxidation peak. It can be supposed, then, that the presence of extra nitrogen in the ring of azaphenothiazine derivatives causes a shift in peaks of oxidation of these compounds towards higher potential values.

\section{Effect of scan rate}

In order to determine the character of the recorded current, the<smiles>[R2]c1ccc2c(c1)N([R20])c1cc([R2])ccc1[S+]2[Si]c1ccccc1N([R20])[Al]</smiles>

Fig. 3 Electrochemical oxidation of 2,10-disubstituted phenothiazines. 


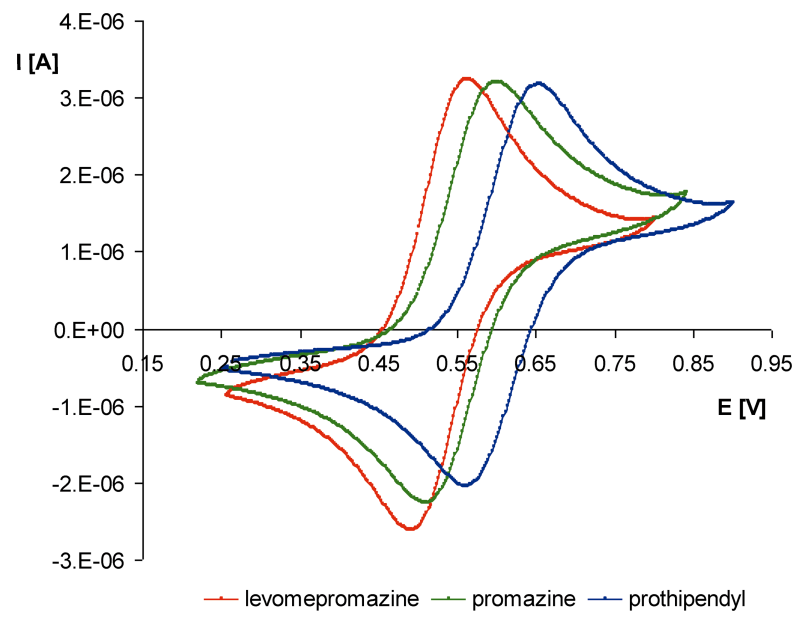

Fig. 4 Cyclic voltammograms of $3.84 \times 10^{-4} \mathrm{~mol} / \mathrm{L}$ levomepromazine, promazine and prothipendyl in $0.1 \mathrm{HClO}_{4}, \mathrm{v}=50 \mathrm{mV} / \mathrm{s}$.

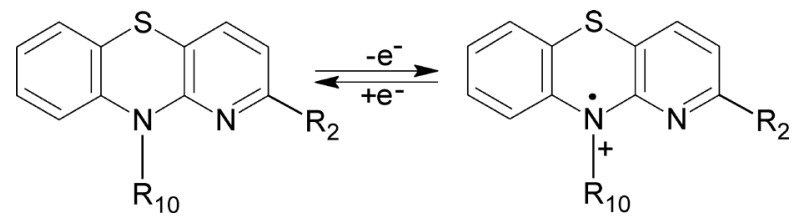

Fig. 5 Electrochemical oxidation of 2,10-disubstituted azaphenothiazines. influence of scan rate on the peak current of oxidation and reduction of the investigated compounds was studied. The measurements were carried out at scan rates from 5 to $500 \mathrm{mV} / \mathrm{s}$. The experiment was conducted in $0.1 \mathrm{~mol} / \mathrm{L}^{\mathrm{HClO}_{4}}$ in the potential range from 0.2 to $0.85 \mathrm{~V}$. Figure $6 \mathrm{~A}$ presents the cyclic voltammograms for levomepromazine. On the basis of cyclic voltammograms recorded at different scan rates, a diagram of current intensity of oxidation peak versus the square root of the scan rate (not shown), as well as the logarithm of current intensity of the oxidation peak of the studied derivatives versus the logarithm of scan rate was plotted (Fig. 6B).

The experiments proved that, with the increase of scan rate, the values of currents also increase. A linear relation was found between the oxidation peak current of phenothiazine derivatives and the square root of the scan rate, as well as a linear relation of the logarithm of peak current versus the logarithm of the scan rate. Slopes $a$ were determined using simple regressions (Fig. 6B) with the general formula $y=a x+b$. The slopes of curves obtained in the logarithmic system are respectively $0.51-0.53$ and are similar to the theoretical value $(0.5)$ typical of the diffusion-controlled process. ${ }^{50}$

\section{Effects of supporting electrolyte and $\mathrm{pH}$ value}

Another experiment aimed at studying the reaction of electrochemical oxidation of phenothiazine and azaphenothiazine derivatives was to check how the kind and $\mathrm{pH}$ of supporting electrolyte affects the voltammetric signal.

For that purpose, supporting electrolytes solutions were prepared in the $\mathrm{pH}$ range from 1 to 7 . The experiments in solutions with $\mathrm{pH}$ higher than 7 caused precipitation of sediments, which eliminated these electrolytes from further research. The following solutions were used for the
A

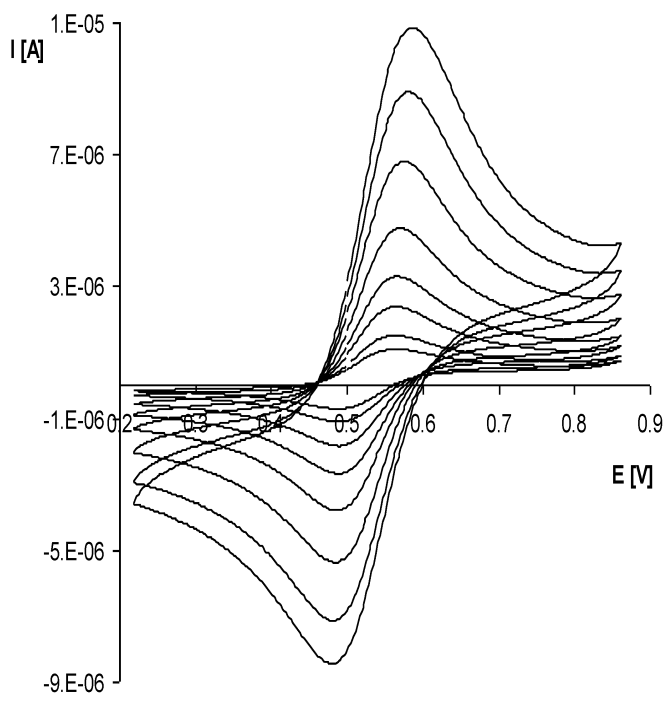

B

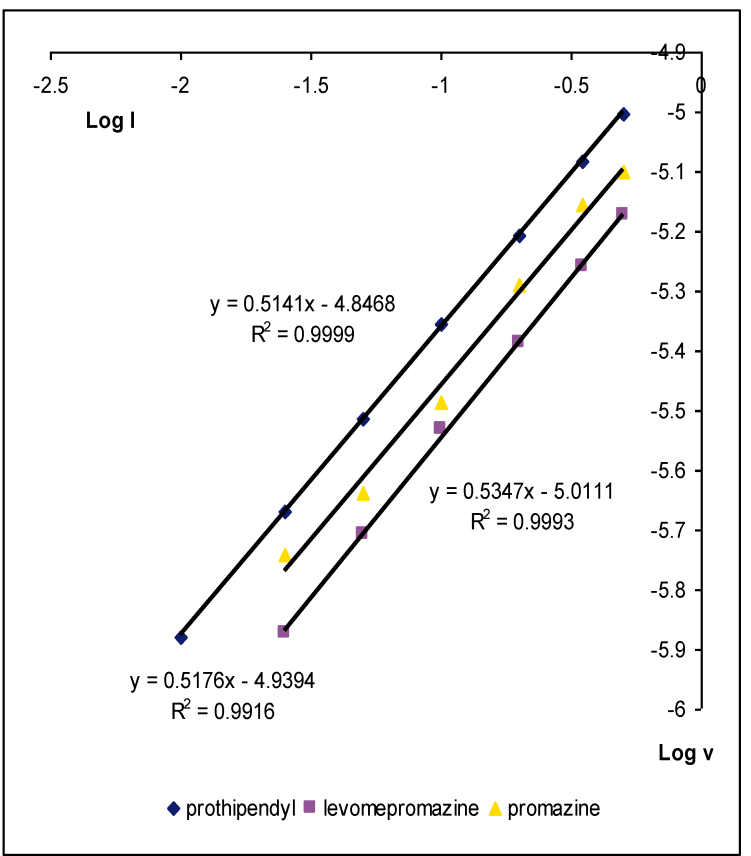

Fig. 6 (A) Cyclic voltammograms of $3.84 \times 10^{-4} \mathrm{~mol} / \mathrm{L}$ levomepromazine in $0.1 \mathrm{~mol} / \mathrm{L} \mathrm{HClO}_{4}$ at different scan rates: $5 ; 10 ; 25 ; 50 ; 100 ; 200 ; 350 ; 500 \mathrm{mV} / \mathrm{s}$ (B) Plot of the logarithm of peak current versus logarithm of scan rate for levomepromazine, promazine, prothipendyl. 


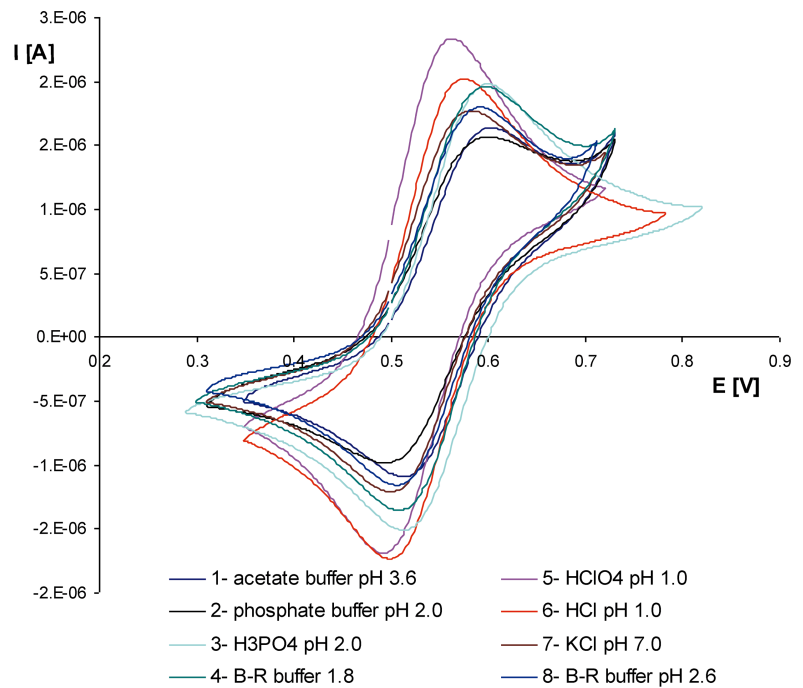

Fig. 7 Cyclic voltammograms of $3.84 \times 10^{-4} \mathrm{~mol} / \mathrm{L}$ levomepromazine in: (1) acetate buffer $\mathrm{pH} 3.6$; (2) phosphate buffer $\mathrm{pH} 2.0$; (3) $0.1 \mathrm{~mol} / \mathrm{L}$ $\mathrm{H}_{3} \mathrm{PO}_{4}$; (4) B-R buffer pH 1.8 (5) $0.1 \mathrm{~mol} / \mathrm{L} \mathrm{HClO}_{4}$; (6) $0.1 \mathrm{~mol} / \mathrm{L} \mathrm{HCl}$; (7) $0.1 \mathrm{~mol} / \mathrm{L} \mathrm{KCl} \mathrm{(8)} \mathrm{B-R} \mathrm{buffer} \mathrm{pH} 2.6, \mathrm{v}=50 \mathrm{mV} / \mathrm{s}$.

measurements: $0.1 \mathrm{~mol} / \mathrm{L} \mathrm{HClO}_{4}$ and $0.1 \mathrm{~mol} / \mathrm{L} \mathrm{HCl}$ with $\mathrm{pH}$ $1.0,0.04 \mathrm{~mol} / \mathrm{L}$ B-R buffer with $\mathrm{pH} 1.8$ and $2.6,0.02 \mathrm{~mol} / \mathrm{L}$ $\mathrm{H}_{3} \mathrm{PO}_{4}$ (pH 2.0), $0.1 \mathrm{~mol} / \mathrm{L}$ phosphate buffer with $\mathrm{pH} 2.0$, $0.2 \mathrm{~mol} / \mathrm{L}$ acetate buffer with $\mathrm{pH} 3.6$ and $0.1 \mathrm{~mol} / \mathrm{L} \mathrm{KCl}$. Using the above-mentioned electrolytes, cyclic voltammograms of the $3.84 \times 10^{-4} \mathrm{~mol} / \mathrm{L}$ phenothiazine and azaphenothiazine derivatives were recorded. The experiments were conducted in the potential range from $0.3 \mathrm{~V}$ to $0.8 \mathrm{~V}$ (within the first, reversible step of the studied compounds), with the scan rate $50 \mathrm{mV} \mathrm{s}^{-1}$.

Figure 7 presents cyclic voltammograms of levomepromazine recorded in the studied solutions. Analogous curves were obtained for the other studied derivatives. Analyzing the obtained results, it was found that peaks of oxidation and reduction of the studied substances were obtained in the whole examined $\mathrm{pH}$ range. Experiments showed that the $\mathrm{pH}$ of the electrolyte does not have a significant influence on the values of the substance's oxidation peak potentials. It complies with the course of the occurring reaction involving a transfer of one electron but no proton exchange (Figs. 3 and 5). The highest and best defined peaks of oxidation of levomepromazine, promazine and prothipendyl were achieved in $0.1 \mathrm{~mol} / \mathrm{L} \mathrm{HClO}_{4}$. In this electrolyte, the difference between peak potentials of oxidation and reduction is similar to the theoretical value $59 / \mathrm{n} \mathrm{mV}$. That is why this solution was chosen as optimal for further studies.

\section{Influence of the electrode material}

The influence of electrode material on the cyclic voltammograms was also studied. In these measurements, the BDD electrode or glassy carbon (GC) electrode was used. The experiment was conducted in $0.1 \mathrm{~mol} / \mathrm{L} \mathrm{KCl}$, applying $3.85 \times$ $10^{-4} \mathrm{~mol} / \mathrm{L}$ of the prothipendyl. The study was carried out in the potential range from $-0.65 \mathrm{~V}$ to $1.2 \mathrm{~V}$ and at the scan rate $50 \mathrm{mV} / \mathrm{s}$. Figures $8 \mathrm{~A}$ and $8 \mathrm{~B}$ present the obtained cyclic voltammograms of the background and the investigated substance at the BDD and GC electrodes, respectively.

On the basis of these voltammograms (Fig. 8), it was found that the oxidation process of the studied compounds is similar at

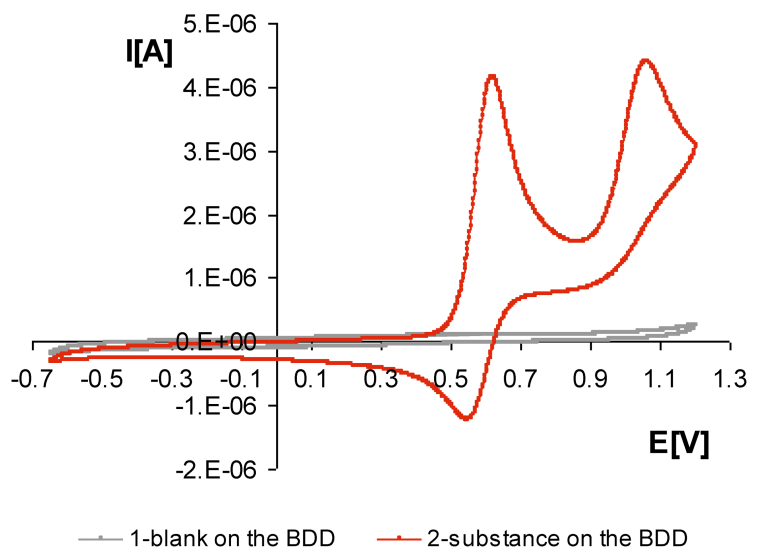

$\mathbf{A}$

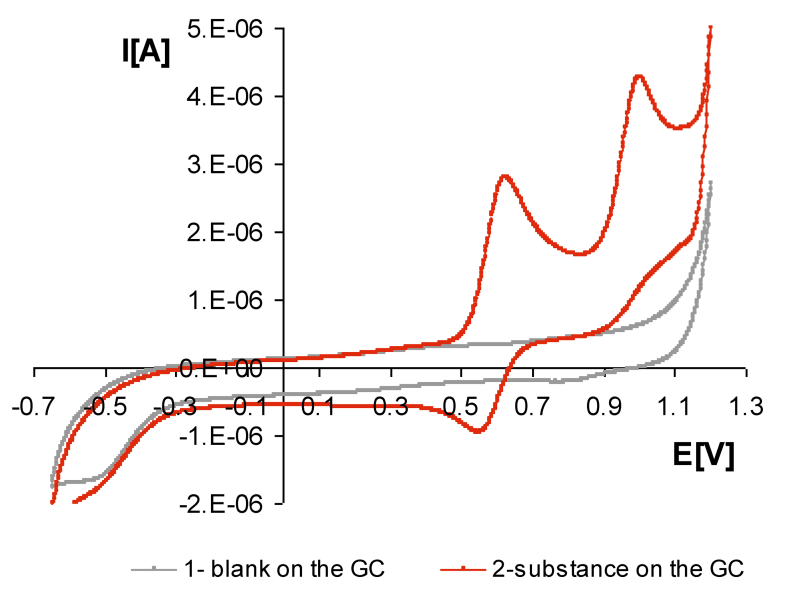

B

Fig. 8 Cyclic voltammograms: (A) on the BDD electrode, (B) on the GC electrode, (1) blank solution, (2) $3.84 \times 10^{-4} \mathrm{~mol} / \mathrm{L}$ prothipendyl in $0.1 \mathrm{~mol} / \mathrm{L} \mathrm{KCl}, \mathrm{v}=50 \mathrm{mV} / \mathrm{s}$.

both electrode materials. A well-defined oxidation peak of the analyte indicated the maximum current intensity at the potential of approx. $0.64 \mathrm{~V}$ both at the BDD and at the glassy carbon electrode. However, the current of prothipendyl oxidation peak at the BDD electrode was higher than the value obtained at the GC electrode. Moreover, at the potential of approx. $1.0 \mathrm{~V}$, another irreversible oxidation peak was observed, and the current obtained at both electrodes were comparable. Experiments showed that the cyclic voltammograms recorded at the BDD electrode have much lower values of background current than the background currents obtained at the GC electrode. Comparing the values of current of the peak of prothipendyl oxidation to the values of background current $(S / B)$, it was found that at the BDD electrode the ratio is 39.5 and at the glassy carbon electrode, 8.15. The measurements showed that the BDD electrode has much higher sensitivity of determinations of the analyzed compounds than the glassy carbon electrode.

\section{Validation of the analytical procedure}

In this work, the square wave voltammetry (SWV) technique and differential pulse voltammetry (DPV) technique were used for quantitative determination of the selected phenothiazine and azaphenothiazine derivatives. So as to choose the optimum 

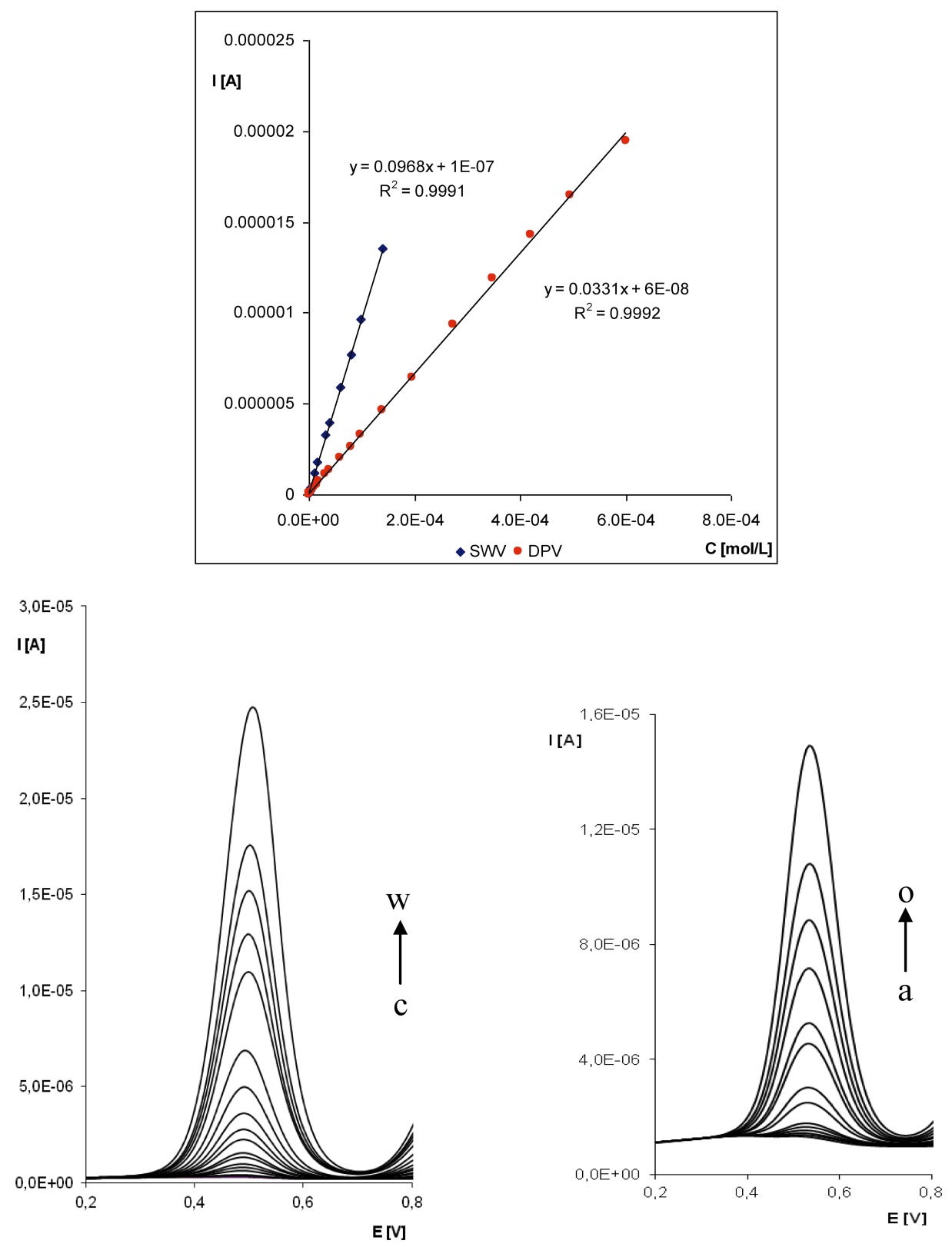

A

Fig. 9 DPV voltammograms (A) and SWV voltammograms (B) for different concentrations of levomepromazine in mol/L: (a) $4 \times 10^{-7}$, (b) $7 \times 10^{-7}$, (c) $9.98 \times 10^{-7}$, (d) $2 \times 10^{-6}$, (e) $3 \times 10^{-6}$, (f) $4 \times$ $10^{-6}$, (g) $9.8 \times 10^{-6}$, (h) $1.46 \times 10^{-5}$, (i) $1.92 \times 10^{-5}$, (j) $3 \times 10^{-5}$, (k) $4 \times 10^{-5}$, (l) $6 \times 10^{-5}$, (m) $7.95 \times 10^{-5}$, (n) $9.9 \times 10^{-5}$, (o) $1.38 \times 10^{-4}$, (p) $1.96 \times 10^{-4}$, (r) $2.72 \times 10^{-4}$, (s) $3.47 \times 10^{-4}$, (t) $4.2 \times 10^{-4}$, (u) $4.94 \times$ $10^{-4}$, (w) $6 \times 10^{-4}$ in $0.1 \mathrm{~mol} / \mathrm{L} \mathrm{HClO}_{4}$ on the BDD electrode (in the window: calibration curves of levomepromazine using DPV and SWV methods).

conditions of the electrochemical oxidation of these substances, the operating parameters of selected techniques were optimized. When choosing the optimum conditions, the height and shape of the recorded peaks of oxidation of the investigated compounds were taken into consideration.

Determining the optimum parameters in the SWV method, the impact of amplitude within the range of $5-100 \mathrm{mV}$ was studied. A linear relation was observed up to $50 \mathrm{mV}$, so this value was recognized as optimum for further studies. The frequency was measured from 8 to $250 \mathrm{~Hz}$. We selected $50 \mathrm{~Hz}$ as the optimal frequency because, high and well-defined peaks were achieved at that frequency. The step potential was analyzed in the range from 2 to $10 \mathrm{mV}$. The highest value of the oxidation peak of selected derivatives was obtained for $2 \mathrm{mV}$.

In the case of the DPV method, the amplitude was measured in the range from 10 to $250 \mathrm{mV}$. The experiments showed an increase of currents with the increase of the amplitude. But the recorded peaks were wider and wider, so $75 \mathrm{mV}$ was recognized as optimum. The scan rate was examined in the range of $5-500 \mathrm{mV} / \mathrm{s}$, but the oxidation peak of studied compounds does not depend on the scan rate in the studied range. Along with the increase of the pulse width in the range of $20-100 \mathrm{~ms}$, 
Table 1 Quantitative determination of levomepromazine, promazine and prothipendyl on the BDD electrode

\begin{tabular}{|c|c|c|c|c|c|c|c|c|c|c|}
\hline Studied substance & Method & $\begin{array}{c}\text { Peak } \\
\text { potential/V } \\
\text { vs. SCE }\end{array}$ & Linearity range $/ \mathrm{mol} / \mathrm{L}$ & $\begin{array}{c}\text { Slope/ } \\
\mu \mathrm{A} \cdot \mathrm{L} / \\
\mathrm{mol}\end{array}$ & $\begin{array}{c}\text { Intercept/ } \\
\mu \mathrm{A}\end{array}$ & $\begin{array}{l}\text { Correlation } \\
\text { coefficient }\end{array}$ & $\begin{array}{l}\mathrm{LOQ} / \\
\mathrm{mol} \mathrm{L}^{-1}\end{array}$ & $\begin{array}{l}\text { LOD/ } \\
\text { mol L-1 }^{-1}\end{array}$ & $\begin{array}{c}\text { Repeata- } \\
\text { bility of } \\
\text { Ip }^{\mathrm{a}} \text {, } \\
\text { RSD } \%\end{array}$ & $\begin{array}{c}\text { Reprodu- } \\
\text { cibility } \\
\text { of Ip } \\
\text { RSD } \%\end{array}$ \\
\hline \multirow[t]{2}{*}{ Levomepromazine } & SWV & 0.516 & $4.0 \times 10^{-7}-1.38 \times 10^{-4}$ & $9.68 \times 10^{4}$ & 0.1 & 0.9991 & $3.89 \times 10^{-7}$ & $1.28 \times 10^{-7}$ & 1.58 & 1.39 \\
\hline & DPV & 0.488 & $9.98 \times 10^{-7}-6.02 \times 10^{-4}$ & $3.31 \times 10^{4}$ & 0.06 & 0.9992 & $8.85 \times 10^{-7}$ & $2.92 \times 10^{-7}$ & 0.89 & 0.33 \\
\hline \multirow[t]{2}{*}{ Promazine } & SWV & 0.545 & $4.0 \times 10^{-7}-1.17 \times 10^{-5}$ & $4.87 \times 10^{5}$ & 0.5 & 0.9993 & $3.91 \times 10^{-7}$ & $1.29 \times 10^{-7}$ & 4.27 & 2.27 \\
\hline & DPV & 0.493 & $9.98 \times 10^{-7}-1.96 \times 10^{-4}$ & $4.24 \times 10^{4}$ & 0.2 & 0.9986 & $8.92 \times 10^{-7}$ & $2.94 \times 10^{-7}$ & 2.48 & 1.21 \\
\hline \multirow[t]{2}{*}{ Prothipendyl } & SWV & 0.604 & $4.95 \times 10^{-7}-4.54 \times 10^{-5}$ & $3.41 \times 10^{4}$ & 0.2 & 0.9982 & $4.85 \times 10^{-7}$ & $1.60 \times 10^{-7}$ & 0.47 & 0.74 \\
\hline & DPV & 0.560 & $1.2 \times 10^{-6}-9.54 \times 10^{-5}$ & $2.25 \times 10^{4}$ & 0.02 & 0.9981 & $1.17 \times 10^{-6}$ & $3.86 \times 10^{-7}$ & 1.26 & 1.44 \\
\hline
\end{tabular}

a decrease of the current was observed. The value of $40 \mathrm{~ms}$ was selected for further studies.

When the best operating parameters were selected, the influence of concentration on the value of recorded currents was studied, from standard substances of levomepromazine, promazine and prothipendyl. So as to determine properties characterizing the proposed measurement methodologies, validation parameters were established, such as: linear relation between current intensity and the concentration of the compound, limit of detection (LOD) and limit of quantification (LOQ), precision, accuracy and selectivity of the developed methods. Quantitative analysis of the selected derivatives was carried out by adding increasing concentrations of the studied analytes to the measurement system, followed by plotting curves of relation of currents of the oxidation peak of selected derivatives versus concentration. Figure 9 presents example results for levomepromazine with the use of the BDD electrode and SWV or DPV methods. The analytical parameters of the determination of the studied derivatives at the BDD electrode are presented in Table 1.

Analyzing the results of experiments obtained at the BDD electrode, lower linear ranges of determination of the studied compounds using the SWV technique can be observed than when using the DPV technique. In addition, the values of slope of calibration curves are higher, which proves higher sensitivity of the SWV method in comparison with the DPV method. On the other hand, using the DPV technique, wider linearity ranges were obtained in comparison with SWV, which can be seen in Fig. 9. The coefficients of determination are close to one, which proves good correlation of results in all the proposed procedures.

In order to check the sensitivity of the proposed procedures, LOD and LOQ of the studied analytes were determined. The values of LOD and LOQ were calculated on the basis of the standard deviation of the background current intensities $(S)$ and the slope of calibration curve $(m)$. The following formulas were applied: ${ }^{51}$

$$
\mathrm{LOD}=3.3 \mathrm{~S} / \mathrm{m}, \mathrm{LOQ}=10 \mathrm{~S} / \mathrm{m} ;
$$

On the basis of the data included in Table 1, it can be said that the developed SWV and DPV methods have good sensitivity, which is proved by the obtained LOD and LOQ values. This also shows that procedures using the BDD electrode are more sensitive than those using the GC electrode ${ }^{20,21}$ and $\mathrm{Hg}$ electrode ${ }^{16}$ or different metallic electrodes (e.g. Pt, Ru, Au). ${ }^{17-19}$

In order to establish the precision of the proposed methods, experiments were conducted verifying the repeatability of measurement results obtained within one day and on five successive days. Then, a statistical analysis of the obtained results was carried out. After a series of experiments and juxtaposing the results in Table 1 , it can be concluded that the developed DPV and SWV methods have very good precision. It is proved by the values of repeatability and reproducibility of the developed methods calculated using relative standard deviation, whose values for the BDD electrode do not exceed $4.27 \%$.

\section{Interference}

The selectivity of the developed procedures used for quantitative determination of phenothiazine and azaphenothiazine derivatives was checked. The influence of interferents on the current of the oxidation peak of the investigated analytes was studied. An excess of each interferent in amounts of 10-, 50-, 100-, 200- and 500-fold in relation to the concentration of the studied substance, amounting to $1.92 \times 10^{-5} \mathrm{~mol} / \mathrm{L}$, was examined. Compounds that can be present in the pharmaceutical preparations were chosen as interferents, e.g., lactose, $\mathrm{SO}_{3}{ }^{2-}$, starch, sodium benzoate, tartaric acid, citric acid, L-ascorbic acid, glucose and glycerol, as well as substances that are electroactive in the studied potential range: $\mathrm{Pb}^{2+}, \mathrm{Cd}^{2+}, \mathrm{Zn}^{2+}$, $\mathrm{Cu}^{2+}, \mathrm{Ca}^{2+}, \mathrm{Mg}^{2+}, \mathrm{Fe}^{2+}$ and $\mathrm{I}^{-}$ions. A substance was recognized as an interferent if a change in voltammetric signal of the analyzed substance was higher than $\pm 5 \%$. The study showed that the greatest interference in the determination of levomepromazine, promazine and prothipendyl occur for iodide ions and L-ascorbic acid, which is the result of their catalytic effect on the process of oxidation of phenothiazine and azaphenothiazine derivatives..$^{52}$ A 10 -fold excess of $\mathrm{I}^{-}$ions and L-ascorbic acid in relation to the determined substance causes an increase of the recorded peaks exceeding the determination error of 5\%. The other studied ions and organic substances are tolerated in much higher concentrations. The weakest interferents were tartaric acid, glucose, starch and benzoic acid and ions such as $\mathrm{Mg}^{2+}, \mathrm{Cd}^{2+}$ and $\mathrm{Ca}^{2+}$, whose 500-fold excess did not affect the result of the analysis.

\section{Assay of phenothiazine and azaphenothiazine derivatives in the} pharmaceuticals

The assay methodology described in the work was used to determine the studied compounds in pharmaceutical preparations: levomepromazine in Tisercin tablets, promazine hydrochloride in Promazine tablets, and prothipendyl hydrochloride in Dominal Forte tablets. The voltammetric measurements were carried out with the use of the SWV method and the BDD electrode. The content of the studied substances in pharmaceutical preparations was determined on the basis of recorded voltammograms of oxidation peaks of these substances and the relevant equation of calibration plots.

On the basis of the obtained data (Table 2), it can be concluded that the applied procedure is characterized with good precision 
Table 2 Results obtained from the SWV determination and recovery experiments of levomepromazine, promazine and prothipendyl in pharmaceuticals on the BDD electrode

\begin{tabular}{|c|c|c|c|c|c|c|c|c|c|c|c|c|c|}
\hline Studied substance & Method & $\begin{array}{c}\text { Labeled } \\
\text { claim/ } \\
\text { mg }\end{array}$ & $\begin{array}{l}\text { Amount } \\
\text { found/ } \\
\mathrm{mg}^{\mathrm{a}}\end{array}$ & S.D. & $\begin{array}{c}\mathrm{RSD} \\
\%\end{array}$ & $\begin{array}{c}\text { Error, } \\
\%\end{array}$ & $\begin{array}{c}\text { Student's } \\
t \text {-test } \\
(2.306)^{\mathrm{b}}\end{array}$ & $\begin{array}{c}F \text {-test } \\
(6.39)^{\mathrm{b}}\end{array}$ & $\begin{array}{c}\text { Added/ } \\
\text { mg }\end{array}$ & $\begin{array}{c}\text { Found/ } \\
\mathrm{mg}^{\mathrm{a}}\end{array}$ & $\begin{array}{c}\text { Recovered, } \\
\%\end{array}$ & $\begin{array}{c}\text { RSD, } \\
\% \text { of } \\
\text { recovery }\end{array}$ & $\begin{array}{c}\text { Error, } \\
\%\end{array}$ \\
\hline \multirow[t]{2}{*}{ Levomepromazine } & SWV & 25 & 24.83 & 0.084 & 0.339 & -0.68 & \multirow[t]{2}{*}{0.82} & \multirow[t]{2}{*}{0.259} & 1.776 & 1.75 & 98.52 & 1.124 & -1.46 \\
\hline & Official method ${ }^{53}$ & 25 & 24.90 & 0.164 & 0.660 & -0.40 & & & 1.776 & 1.766 & 99.46 & 0.963 & -0.40 \\
\hline \multirow[t]{2}{*}{ Promazine } & SWV & 25 & 24.86 & 0.083 & 0.333 & -0.56 & \multirow[t]{2}{*}{1.189} & \multirow[t]{2}{*}{5.68} & 2.035 & 2.016 & 99.07 & 0.893 & -0.56 \\
\hline & Official method ${ }^{53}$ & 25 & 24.97 & 0.197 & 0.790 & -0.12 & & & 2.035 & 2.026 & 99.57 & 0.498 & -0.12 \\
\hline \multirow[t]{2}{*}{ Prothipendyl } & SWV & 40 & 39.90 & 0.048 & 0.119 & -0.25 & \multirow[t]{2}{*}{1.13} & \multirow[t]{2}{*}{5.61} & 1.610 & 1.600 & 99.40 & 0.59 & -0.25 \\
\hline & Official method ${ }^{53}$ & 40 & 39.83 & 0.112 & 0.283 & -0.42 & & & 1.610 & 1.601 & 99.46 & 0.87 & -0.32 \\
\hline
\end{tabular}

a. Each value is the mean from five experiments, b. The values in parenthesis are corresponding to the theoretical values of $t$ and $F$ at $(P=0.05)$.

of determinations, which is proved by the low values of relative standard deviation $0.79 \%$ and the low error of determination in relation to the values declared by the manufacturers, approximately $0.68 \%$. Comparing the developed procedure using the BDD electrode and the pharmacopoeial methods recommended in the literature, ${ }^{53}$ it can be concluded that they are similar and are characterized by very good precision of determinations of the studied compounds.

In order to estimate the accuracy of the developed method, its recovery was also determined. The experiment was carried out using the standard addition method. A known amount of pure substance was added to the solution containing a known amount of a pharmaceutical preparation. Current values of oxidation peaks of the selected substances were recorded, and the obtained current values were used to calculate the recovery.

The data presented in Table 2 show that the proposed procedures have high accuracy of measurements. It is proved by high values of recovery $(98.52-99.46 \%)$ and low values of relative standard deviation $(0.59-1.12 \%)$. The error of determination of the studied substances in drug samples in relation to the values declared is in the range $0.12-1.46 \%$. The proposed procedure using the SWV technique and the BDD electrode can be used for quantitative determination of the analyte in different pharmaceutical samples.

\section{Conclusions}

The work presents new, attractive methods of determination of selected phenothiazine and azaphenothiazine derivatives with the use of the BDD electrode. The described procedures involve the reactions of electrochemical oxidation of selected compounds to the form of radical cations. The BDD electrode is an excellent tool to analyze this group of compounds. The proposed procedures are sensitive, precise, selective and perfectly suitable for the determination of the analyzed substances in different pharmaceutical preparations. Experiments conducted with the use of the BDD electrode considerably simplify the analysis process. It results from the specific properties of the BDD electrode in comparison to conventional electrodes. Moreover, the BDD electrode is characterized by low adsorption of polar molecules, which eliminates the problem of frequent and timeconsuming cleaning. Therefore, it is possible to carry out a high number of determinations with good repeatability in a very short time, and every three months the BDD electrode can be plunged in ethanol, making it ready for work again. Comparative studies at different electrode materials showed that the sensitivity of measurements at the BDD electrode is higher in comparison with the results obtained at the GC electrode. In the case of prothipendyl, it was observed that the signal-to-background ratio $(S / B)$ is 39.5 for the BDD electrode and 8.15 for the glassy carbon electrode.

To summary, the proposed methods are quick, do not require any special preparation of the sample, concentration, isolation from the matrix or expensive and complex equipment. They are a great alternative to pharmacopoeial methods, and they meet all the requirements of Green Chemistry.

\section{Acknowledgements}

We owe our gratitude to Mr. Javier Sepulveda Chamizo at the University of Valencia (Spain) for his technical assistance.

\section{References}

1. R. R. Gupta, "Bioactive Molecules", in "Phenothiazines and 1,4-Benzothiazines, Chemical and Biomedical Aspects", Vol. 4, 1988, Elsevier, Amsterdam.

2. H. Puzanowska-Tarasiewicz, L. Kuźmicka, J. Karpińska, and K. Mielech-Łukasiewicz, Anal. Sci., 2005, 21, 1149.

3. T. Kumazawa, C. Hasegawa, S. Uchigasaki, and X. Lee, J. Chromatogr. A, 2011, 1218, 2521.

4. Q. Xiao and B. Hu, J. Chromatogr. B, 2010, 878, 1599.

5. M. C. Quintana, J. J. Ramos, L. Hernandez, and L. Ramos, J. Liq. Chromatogr., 2010, 33, 270.

6. M. Cruz-Vera, R. Lucena, S. Cardenas, and M. Valcarcel, $J$. Chromatogr. B, 2009, 877, 37.

7. C. Pistos and J. T. Stewart, Biomed. Chromatogr., 2003, 17, 465.

8. M. C. Quintana, M. H. Blanco, J. Lacal, and L. Hernandez, Talanta, 2003, 59, 417.

9. M. Wójciak-Kosior, A. Skalska, and A. Matysik, J. Pharm. Biomed. Anal., 2006, 41, 286.

10. A. El-Didamony and S. Hafeez, Spectrosc. Int. J., 2012, 27, 129.

11. S. M. Oliveira, M. A. Segundo, A. O. S. S. Rangel, J. L. F. C. Lima, and V. Cerda, Anal. Lett., 2011, 44, 284.

12. H. Puzanowska-Tarasiewicz and J. Karpińska, Acta Pol. Pharm., 2003, 60, 409.

13. K. Nemcova, P. Nesmerak, J. Rychlovsky, and J. Koutnikova, Talanta, 2005, 65, 632.

14. Y. Li, W. Niu, and J. Lu, Talanta, 2007, 71, 1124.

15. C. C. Nascentes, S. Cardenas, M. Gallego, and M. Valcarcel, Anal. Chim. Acta, 2002, 462, 275. 
16. F. Belal, S. El-Ashry, I. Shehata, M. A. El-Sherbeny, and D. T. El-Sherbeny, Microchim. Acta, 2000, 135, 147.

17. S. Dermis and J. Biryol, Analyst, 1989, 114, 525.

18. S. A. Ozkan, Z. Senturk, B. Uslu, and I. Biryol, J. Pharm. Biomed. Anal., 1996, 15, 365.

19. L. Huang, L. Bu, F. Zhao, and B. Zeng, J. Solid. State Electrochem., 2004, 8, 976.

20. R. V. Sandulescu, S. M. Mirel, R. N. Oprane, and S. Lotrean, Collect. Czech. Chem. Commun., 2000, 65, 1014.

21. K. Mielech-Łukasiewicz, H. Puzanowska-Tarasiewicz, and A. Panuszko, Anal. Lett., 2008, 41, 789.

22. M. H. Parvin, Electrochem. Commun., 2011, 13, 366.

23. M. A. Karimi, A. Hatefi-Mehrjardi, M. M. Ardakani, R. B. Ardakani, M. H. Mashhadizadeh, and S. Sargazi, Russ. J. Electrochem., 2011, 47, 34.

24. A. Ensafi and E. Heydari, Anal. Lett., 2008, 41, 2487.

25. Y. Ni, L. Wang, and S. Kokot, Anal. Chim. Acta, 2001, 439, 159.

26. M. Vanickova, M. Buckova, and J. Labuda, Chem. Anal. (Warsaw), 2000, 45, 125.

27. R. Y. Hwang, G.. Xu, J. Han, J. Y. Le, H. N. Choi, and W. Lee, J. Electroanal. Chem., 2011, 656, 258.

28. A. Ferancova, E. Korgova, T. Buzinkaiova, W. Kutner, I. Stepanek, and J. Labuda, Anal. Chim. Acta, 2001, 447, 47.

29. B. Zeng, Y. Yang, X. Ding, and F. Zhao, Talanta, 2003, 61 , 819.

30. R. B. Channon, J. C. Newland, A. W. T. Bristow, A. D. Ray, and J. V. Macpherson, Electroanalysis, 2013, 25, 2613.

31. B. Zeng and F. Huang, Talanta, 2004, 64, 380.

32. J. P. Marco, Sens. Actuators, B, 2013, 177, 251.

33. B. Unnikrishnan, P. Hsu, and S. Chen, Int. J. Electrochem. Sci., 2012, 7, 11414.

34. Y. Einaga, J. Appl. Electrochem., 2010, 40, 1807.

35. J. H. T. Luong, K. M. Male, and J. D. Glennon, Analyst, 2009, 134, 1965.

36. K. Peckova, J. Musilova, and J. Barek, Crit. Rev. Anal.
Chem., 2009, $39,148$.

37. Y. Zhou and J. Zhi, Talanta, 2009, 79, 1189.

38. P. De Lima-Neto, A. Correia, R. Portela, M. J. De Silva, G. Linhares-Junior, and J. De Lima, Talanta, 2010, 80, 1730.

39. L. Svorc, D. M. Stankovic, E. Mehmeti, and K. Kalcher, Anal. Methods, 2014, 13, 4853.

40. R. M. Dornellas, D. B. Nogueira, and R. Q. Aucelio, Anal. Methods, 2014, 6, 944.

41. K. Mielech-Łukasiewicz and K. Rogińska, Anal. Methods, 2014, 6, 7912.

42. E. R. Sartori, R. Medeiros, R. Rocha-Filho, L. Mazo, and O. Fatibello-Filho, Talanta, 2010, 81, 1418.

43. K. D. Santos, O. C. Braga, I. C. Vieira, and A. Spinelli, Talanta, 2010, 80, 1999.

44. S. Fierro, C. Comninellis, and Y. Einaga, Talanta, 2013, 103, 33.

45. J. C. Harfield, K. E. Toghill, C. Batchelor-Mcauley, C. Downing, and R. G. Compton, Electroanalysis, 2011, 23, 931.

46. K. E. Toghill, L. Ciao, G. G. Wildgoose, and R. G. Compton, Electroanalysis, 2009, 21, 1113.

47. S. Fierro, T. Watanabe, K. Akai, and Y. Einaga, Electrochim. Acta, 2012, 82, 9.

48. M. C. Granger, J. S. Xu, J.W. Strojek, and G. M. Swain, Anal. Chim. Acta, 1999, 379, 145.

49. F. W. P. Ribeiro, A. S. Cardoso, R. R. Portela, J. E. S. Lima, S. A. S. Machado, P. De Lima-Neto, D. De Souza, and A. N. Correia, Electroanalysis, 2008, 20, 2031.

50. Z. Galus, "Fundamentals of Electrochemical Analysis", 1994, Ellis Horwood Press.

51. J. C. Miller and J. N. Miller, "Statistics for Analytical Chemistry", 1988, Ellis Horwood, Chichester, UK, New York.

52. E. Kleszczewska and K. Mielech, J. Trace Microprobe Tech., 2003, 21, 203.

53. Polish Pharmacopoeia IX, 2012, PTF, Warsaw. 